\title{
Case Report \\ Humerus Diaphysis Fracture in a Newborn during Vaginal Breech Delivery
}

\author{
Baris Kaya, ${ }^{1}$ Korkut Daglar, ${ }^{1}$ Ayse Kirbas, ${ }^{2}$ and Abdullah Tüten ${ }^{1}$ \\ ${ }^{1}$ Gaziantep Maternity Hospital, Gaziantep, Turkey \\ ${ }^{2}$ Department of Perinatology, Zekai Tahir Burak Women's Health Education and Research Hospital, 06680 Ankara, Turkey \\ Correspondence should be addressed to Ayse Kirbas; drayse1982@yahoo.com
}

Received 24 October 2015; Accepted 24 November 2015

Academic Editor: Loïc Sentilhes

Copyright (C) 2015 Baris Kaya et al. This is an open access article distributed under the Creative Commons Attribution License, which permits unrestricted use, distribution, and reproduction in any medium, provided the original work is properly cited.

\begin{abstract}
While most obstetricians are familiar with fracture of the clavicle in newborns during birth, an unlucky minority of obstetricians has encountered long-bone fractures in newborns as well. This complication is traumatic not only for the neonate, but also for the family and the obstetrician; it is also difficult to explain. Fortunately, the long-term prognosis for fracture of the long bones is excellent. Both vaginal and cesarean breech deliveries and maneuvers can be responsible for birth traumas, including long-bone fractures. This case report presents a newborn with breech presentation delivered vaginally that resulted in humerus diaphysis fracture.
\end{abstract}

\section{Introduction}

Most obstetricians are familiar with fracture of the clavicle in newborns during birth; however, an unlucky few have encountered long-bone fractures in newborns as well. These fractures are traumatic not only for the neonate, but also for the family and the obstetrician; they are also difficult to explain. Although it has been reported that cesarean delivery may reduce the incidence of long-bone fractures, they still occur $[1,2]$. Breech delivery, by either vaginal or cesarean route, remains the most common independent factor for long-bone fractures [1-3].

There is limited data regarding vaginal breech delivery after cesarean section [2-4]. To the best of our knowledge, there have been no reports of humerus or any other longbone fracture after vaginal breech delivery with a scarred uterus. Herein, we describe a case of humerus diaphysis fracture in a newborn.

\section{Case Presentation}

A 35-year-old woman, gravida 3, para 2, was admitted to our hospital in active labor with a frank breech presentation in the 39th week. She had delivered her first baby vaginally four years earlier and her second baby by cesarean section due to fetal distress three years earlier. This time, she requested a vaginal delivery, and written informed consent was obtained. Her labor progressed spontaneously. Once the scapula was visible, the obstetrician rotated the infant $90^{\circ}$ and gently swept the anterior arm by pressing on the inner aspect of the elbow, but the maneuver failed. The obstetrician then rotated the infant $180^{\circ}$ in the reverse direction and swept the right arm out of the vagina; however, the left arm was still in the uterus. Despite attempting all types of maneuvers, the left arm could not be rescued. The pulsation rate of the umbilical cord was dropping, so the staff had to apply traction forcefully to the left arm to rescue it. After the left humerus broke with an audible "crack," the head of the baby quickly delivered. The male baby's weight was $3500 \mathrm{~g}$, and his one- and five-minute Apgar scores were 5 and 8, respectively.

The baby's broken arm (Figure 1(a)) was fixed to his body with a bandage and an orthopedic specialist was consulted. With immobilization, the baby's arm healed completely, without any deformity (Figure 1(b)).

\section{Discussion}

Forced obstetric maneuvers have been reported as a risk of soft-tissue injury, long-bone fractures, and related neonatal complications. Historically, long-bone fractures have been 


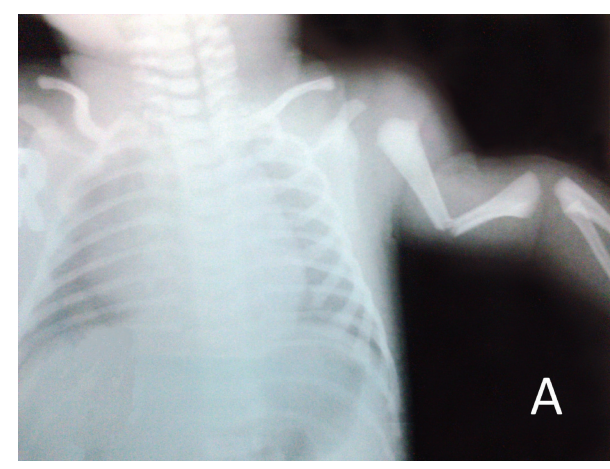

(a)

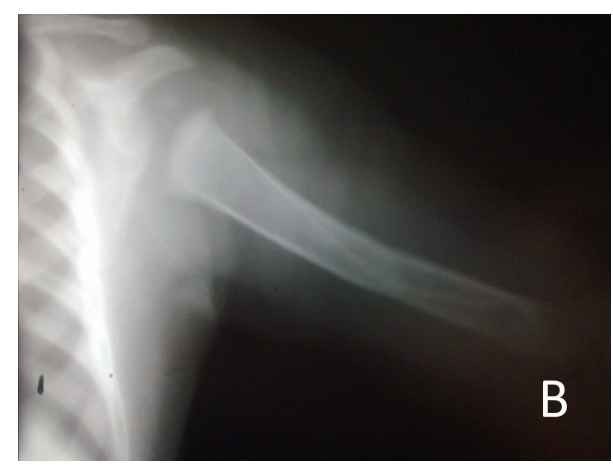

(b)

FIGURE 1: (a) Radiograph of fractured humerus prior to reduction and immobilization. (b) After 2 months.

attributed to breech maneuvers during vaginal delivery; however, because cesarean deliveries are becoming more popular and include breech maneuvers, the incidence of long-bone fractures may be on the increase. Abdominal and vaginal delivery maneuvers are similar in breech presentation $[4,5]$; while cesarean section avoids the risk of head entrapment, long-bone trauma can still occur [4-7].

Attempting a vaginal breech delivery after cesarean section is a challenging undertaking, and the rates of vaginal birth after cesarean section have been declining in recent years [4]. Nonetheless, with careful selection of patients and strict management of labor, vaginal birth does not seem to increase maternal or neonatal morbidity or mortality in this situation [6-8].

The incidence rate of long-bone injuries has been reported as $0.23-0.67$ per 1,000 live births $[9,10]$. To the best of our knowledge, there is only one case report in the literature of humerus fracture in a neonate related to breech vaginal delivery [3], and a few others have been reported in long-bone fracture series of newborns related to vaginal delivery [5].

In a series of seven neonates who sustained a birth-related fracture of the humerus, three cases were breech presentation, only one of which was due to vaginal breech delivery. Surprisingly, a significant number of fractures occurred in babies born via cesarean section unrelated to the presentation, which is considered to be safer than vaginal delivery [10]. Similarly, in their retrospective long-bone fracture series, Basha et al. concluded that emergency cesarean delivery carries a higher risk of long-bone fracture than vaginal delivery [5].

Forced breech maneuvers in both vaginal and cesarean routes of delivery, as well as emergency cesarean section, can cause fetal injuries, including long-bone fractures. Fortunately, humerus fractures heal with simple immobilization, without long-term deformity [11].

In conclusion, long-bone fractures are still one of the most feared complications of birth. It should be emphasized that cesarean section does not eliminate the possibility of longbone fractures. It is important to inform patients scheduled for delivery due to breech presentation that long-bone fractures may occur due to the maneuvers performed during delivery. More importantly, it should also be emphasized that the risk cannot be eliminated completely, even if a cesarean section is performed. If the delivery is difficult, the newborn might experience trauma. Early detection of such traumas, including long-bone fractures, is very important; thus, a thorough examination and assessment are essential in the early period after the birth. A higher index of suspicion would help with early detection and treatment.

\section{Consent}

The patient gave consent for the publication of the clinical details.

\section{Disclosure}

This case report was presented as a poster presentation at the 13th World Congress in Fetal Medicine, June 29-July 3, 2014, Nice, France.

\section{Conflict of Interests}

The authors declare that there is no conflict of interests regarding the publication of this paper.

\section{References}

[1] N. Linder, I. Linder, E. Fridman et al., "Birth trauma-risk factors and short-term neonatal outcome," The Journal of Maternal-Fetal \& Neonatal Medicine, vol. 26, no. 15, pp. 14911495, 2013.

[2] H. Caviglia, C. P. Garrido, F. F. Palazzi, and N. V. Meana, "Pediatric fractures of the humerus," Clinical Orthopaedics and Related Research, vol. 432, pp. 49-56, 2005.

[3] P. Dunkow, M. J. Willett, and L. Bayam, "Fracture of the humeral diaphysis in the neonate," Journal of Obstetrics and Gynaecology, vol. 25, no. 5, pp. 510-511, 2005.

[4] A. Bourtembourg, M. Mangin, R. Ramanah, R. Maillet, and D. Riethmuller, "Breech delivery and scarred uterus: a special obstetrical situation?" Journal de Gynécologie Obstétrique et Biologie de la Reproduction, vol. 42, no. 4, pp. 351-358, 2013.

[5] A. Basha, Z. Amarin, and F. Abu-Hassan, "Birth-associated long-bone fractures," International Journal of Gynecology and Obstetrics, vol. 123, no. 2, pp. 127-130, 2013. 
[6] S. Papp, G. Dhaliwal, G. Davies, and D. Borschneck, "Fetal femur fracture and external cephalic version," Obstetrics and Gynecology, vol. 104, no. 5, pp. 1154-1156, 2004.

[7] S. Matsubara, A. Izumi, T. Nagai, I. Kikkawa, and M. Suzuki, "Femur fracture during abdominal breech delivery," Archives of Gynecology and Obstetrics, vol. 278, no. 2, pp. 195-197, 2008.

[8] F. E. Canpolat, A. Köse, and M. Yurdakök, "Bilateral humerus fracture in a neonate after cesarean delivery," Archives of Gynecology and Obstetrics, vol. 281, no. 5, pp. 967-969, 2010.

[9] I. Al-Habdan, "Birth-related fractures of long bones," Indian Journal of Pediatrics, vol. 70, no. 12, pp. 959-960, 2003.

[10] N. Sherr-Lurie, G. M. Bialik, A. Ganel, A. Schindler, and U. Givon, "Fractures of the humerus in the neonatal period," Israel Medical Association Journal, vol. 13, no. 6, pp. 363-365, 2011.

[11] C. A. Popkin, W. N. Levine, and C. S. Ahmad, "Evaluation and management of pediatric proximal humerus fractures," Journal of the American Academy of Orthopaedic Surgeons, vol. 23, no. 2, pp. 77-86, 2015. 


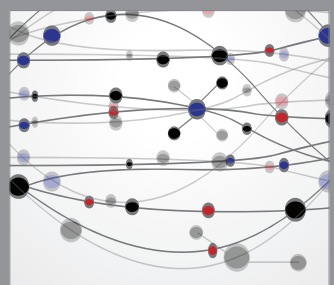

The Scientific World Journal
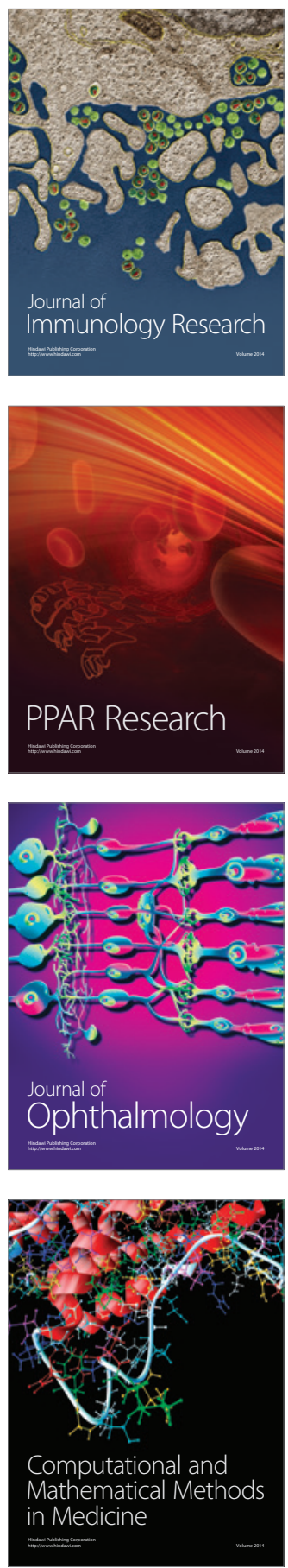

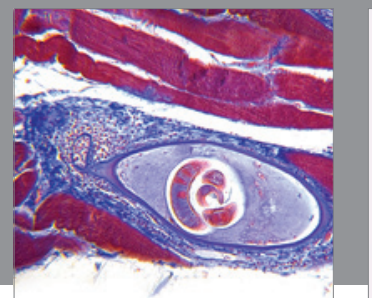

Gastroenterology

Research and Practice
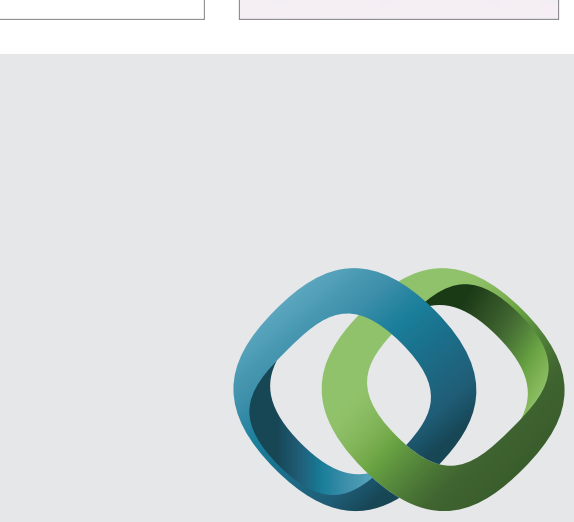

\section{Hindawi}

Submit your manuscripts at

http://www.hindawi.com
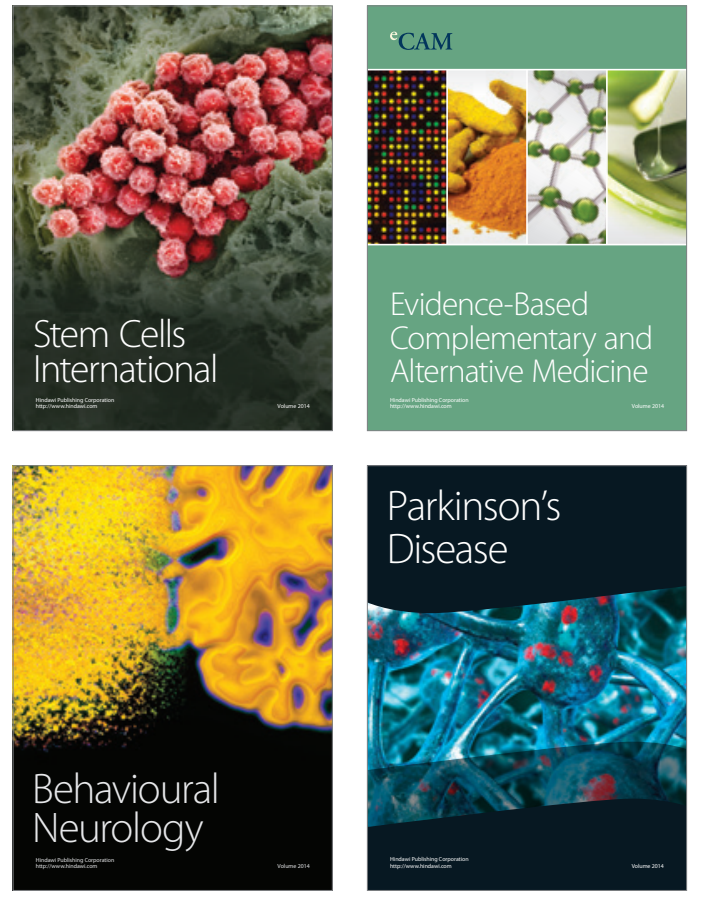
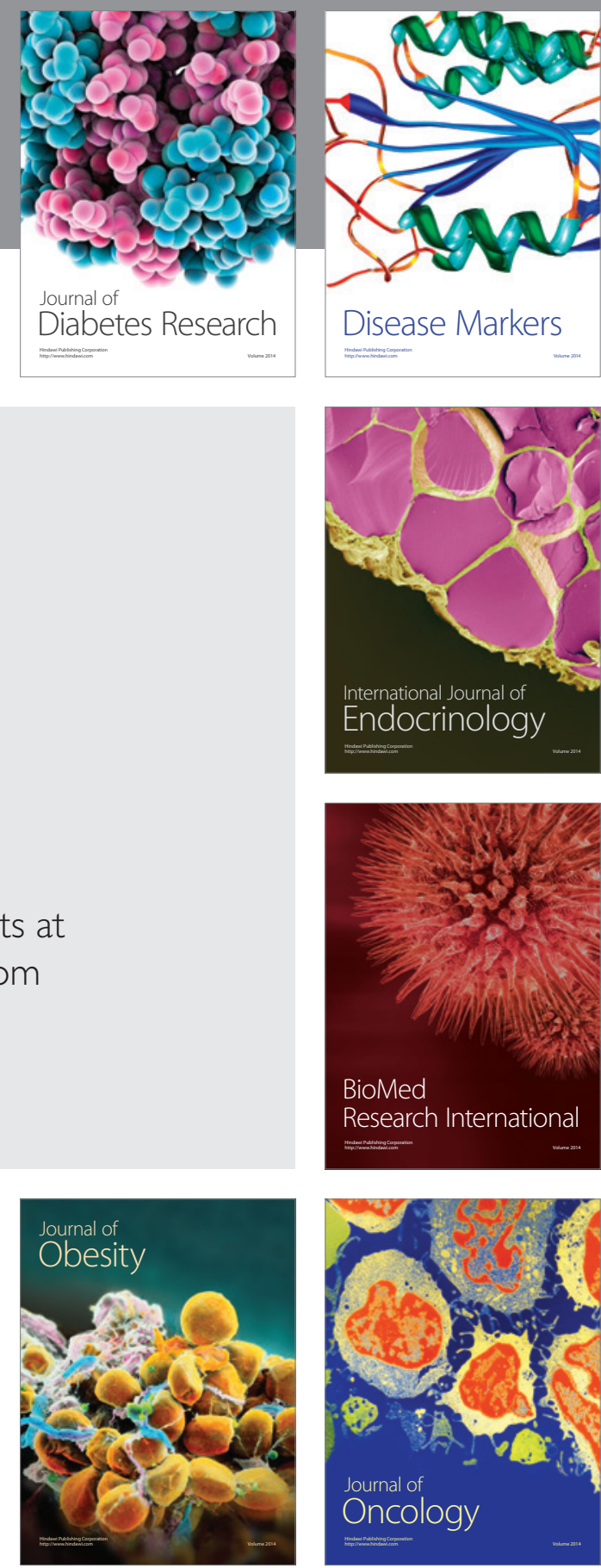

Disease Markers
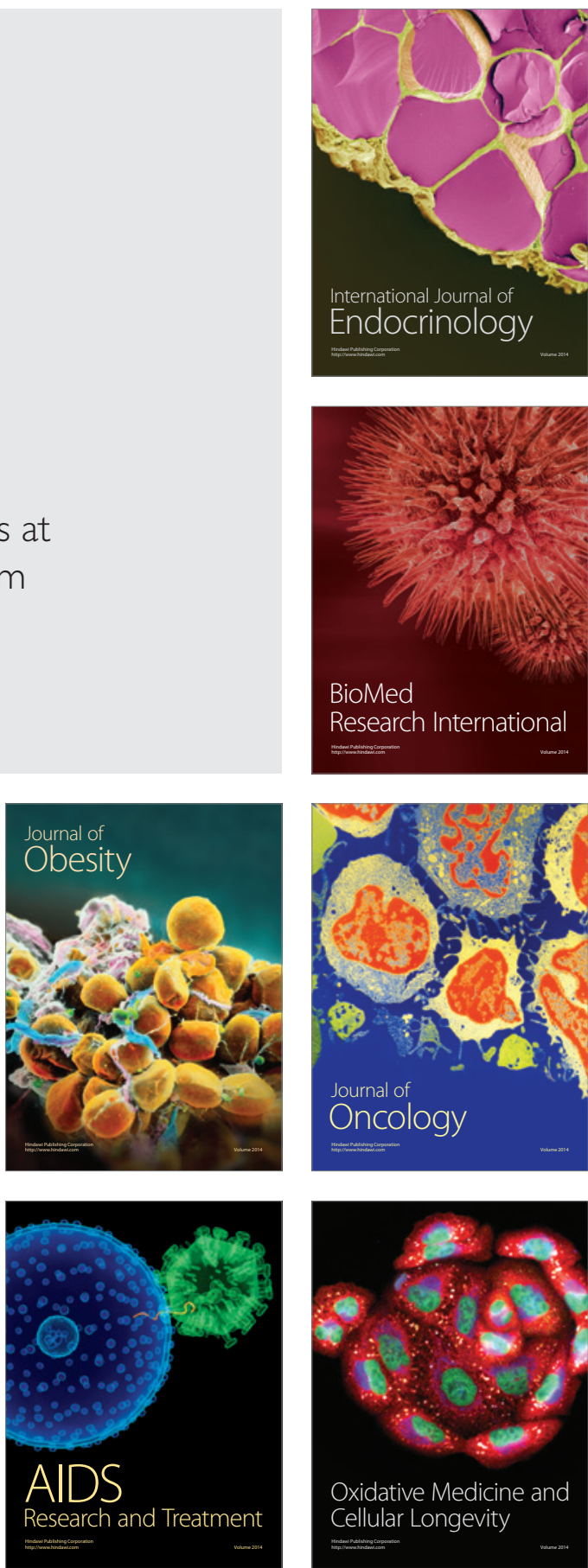